\title{
A Methodology for Predicting Hybrid Solar Panel Performance in Different Operating Modes
}

Jamie P. Fine, Seth B. Dworkin*, and Jacob Friedman

Department of Mechanical and Industrial Engineering

Ryerson University

350 Victoria Street, Toronto, Canada

(*Corresponding author: seth.dworkin@ryerson.ca) 


\begin{abstract}
When a hybrid solar panel produces thermal energy, it can operate in either hybrid mode, or thermal-only mode. In hybrid mode, the panel produces both electrical power and thermal power, and in thermal-only mode, only thermal power is produced. It has been shown that the thermal performance of a hybrid panel can vary by $15 \%$ on average between these two modes, but panel manufacturers are only required to publish performance data for one mode. Other studies in the literature have found a difference in panel thermal performance between these two modes, but they do not discuss a methodology to estimate alternate mode performance using manufacturer-supplied data. To alleviate this gap in the literature, this study presents a novel methodology to estimate alternate mode thermal performance of a hybrid solar panel only using manufacturer-supplied data. To match the panel information that is typically available, the second-order thermal efficiency model is used to estimate thermal performance, and temperature dependent electrical characteristics are used to estimate electrical performance. Indoor testing using a solar simulator was carried out, and the detailed test results are included. Results show that using the proposed modification technique can estimate thermal performance within $4 \%$ of actual values on average.
\end{abstract}

Keywords: Solar; Hybrid Panel; PVT Panel; Experimental Data; Efficiency 


\begin{tabular}{|c|c|c|}
\hline Symbol & Description & Units \\
\hline$\alpha$ & panel temperature coefficient & $\% / K$ \\
\hline$\eta_{0}$ & panel performance coefficient 1 & $\%$ \\
\hline$\eta_{e}$ & electrical efficiency of the panel & $\%$ \\
\hline$\eta_{e_{\max }}$ & maximum electrical efficiency & $\%$ \\
\hline$\eta_{e_{\min }}$ & minimum electrical efficiency & $\%$ \\
\hline$\eta_{e_{r e f}}$ & $\begin{array}{l}\text { panel electrical power produced at the panel reference } \\
\text { temperature }\end{array}$ & $\%$ \\
\hline$\eta_{t h}$ & thermal efficiency & $\%$ \\
\hline$\eta_{t h_{\max }}$ & maximum thermal efficiency & $\%$ \\
\hline$\eta_{t h_{\text {min }}}$ & minimum thermal efficiency & $\%$ \\
\hline$a_{1}$ & panel performance coefficient 2 & $W / m^{2} K$ \\
\hline$a_{2}$ & panel performance coefficient 3 & $W / m^{2} K^{2}$ \\
\hline$A_{\text {panel }}$ & $\begin{array}{l}\text { panel area used in the thermal efficiency parameter } \\
\text { determination }\end{array}$ & $m^{2}$ \\
\hline$c_{p}$ & specific heat capacity of the fluid in the panel & $\mathrm{J} / \mathrm{kg}$ \\
\hline$\dot{E}$ & electrical power generated by the panel & $W$ \\
\hline$G$ & incident solar irradiation on the panel & $W / m^{2}$ \\
\hline$G_{\max }$ & maximum incident solar irradiation on the panel & $W / m^{2}$ \\
\hline$G_{\min }$ & minimum incident solar irradiation on the panel & $W / m^{2}$ \\
\hline$G_{n}^{\prime}$ & modified solar flux for modification case $n$ & $W / m^{2}$ \\
\hline$\dot{m}$ & mass flow rate of the fluid in the panel & $\mathrm{kg} / \mathrm{s}$ \\
\hline$\dot{Q}_{\text {panel }}$ & thermal power generated by the panel & $W$ \\
\hline$\dot{Q}_{\text {panel }}^{\prime}$ & modified thermal power generated by the panel & $W$ \\
\hline$\dot{Q}_{\max }$ & maximum useful heat generated & $W$ \\
\hline$\dot{Q}_{\min }$ & minimum useful heat generated & $W$ \\
\hline$T_{a}$ & ambient temperature & ${ }^{\circ} \mathrm{C}$ \\
\hline$T_{\text {in }}$ & inlet fluid temperature & ${ }^{\circ} \mathrm{C}$ \\
\hline$T_{m}$ & mean panel temperature & ${ }^{\circ} \mathrm{C}$ \\
\hline$T_{\text {out }}$ & outlet fluid temperature & ${ }^{\circ} \mathrm{C}$ \\
\hline$T_{\text {panel }}$ & panel temperature of interest & ${ }^{\circ} \mathrm{C}$ \\
\hline$T_{r}$ & panel reduced temperature & $m^{2} K / W$ \\
\hline$T_{r}{ }^{\prime}$ & modified reduced temperature & $m^{2} K / W$ \\
\hline$T_{r_{\max }}$ & maximum reduced temperature & $m^{2} K / W$ \\
\hline$T_{r_{\min }}$ & minimum reduced temperature & $m^{2} K / W$ \\
\hline$T_{r e f}$ & panel reference temperature & ${ }^{\circ} \mathrm{C}$ \\
\hline
\end{tabular}




\section{Introduction}

\subsection{Research Motivation}

The use of solar panels is becoming more popular as concerns of GHG emissions increase, and because solar energy is renewable and increasingly affordable. There is a wide variety of solar panel types that are commercially available, which can produce thermal energy (converting solar radiation into heating a working fluid), electrical energy (by photovoltaic conversion), or both. Photovoltaic-thermal (PVT) panels can produce both forms of energy, and are often referred to as 'hybrid panels'. These hybrid panels will be the focus of this article.

When testing and characterizing the performance of solar panels, standard testing procedures are often used, and one popular choice is ISO:9806-2017 [1]. Using this standard testing procedure, the thermal performance of a panel is characterized as a function of operating conditions, using second-order thermal efficiency parameters [2]. This thermal efficiency characterization is often published by manufacturers such that engineers and researchers can estimate the panel performance for a given application. However, one drawback of this standard testing and characterization procedure is encountered when a hybrid panel is being considered. The testing standard only requires that the thermal performance of the panel be characterized when electricity is, or is not, being produced. Therefore, this can lead to scenarios where the thermal performance of the panel has been characterized in a different operating mode than the test condition. This paper will focus on investigating the implications that this different operating mode characterization can have on hybrid panel thermal performance. A modification methodology that uses manufacturer-provided thermal and electrical performance parameters, but can account for the different operating mode conditions, is presented. This modification 
methodology is supported by experimental test results, which were generated using an indoor solar simulator.

\subsection{Overview of hybrid solar panels}

Hybrid solar panels offer the option to produce both heat and electricity from one panel, which can be necessary when there are space constraints for a given project. When looking to purchase a hybrid panel, there are options related to the fluid that can be used to extract heat from the panel. When a liquid is used, the fluid is often water, or a water-antifreeze mixture if cold temperatures are expected during operation. When a gas is used, air is often used as the fluid in either an open or closed loop system. Testing of both types of hybrid panels has shown that electrical performance improvements of up to $7 \%$ can be achieved compared to conventional photovoltaic (PV) panels [3]. This increase in electrical performance is due to lower PV cell temperatures caused by heat removal, which is another benefit of using hybrid panels [4].

Liquid-based hybrid panels can offer efficiency improvements compared to air-based panels, with typical thermal efficiencies of $45 \%$ to $79 \%$ [5], since water is a better heat-carrying fluid than air [6]. This improved performance allows for increased system operating temperatures, and better heat transfer to system thermal loads. Some applications of liquid-based hybrid panels include space heating [5], water heating [7], and water distillation [8]. However, some drawbacks of liquid-based systems include the maintenance required to ensure leaks do not develop in the piping network, along with the degradation of water-antifreeze mixtures at times when there are temperatures that exceed $121^{\circ} \mathrm{C}$ [9]. A schematic of a liquid-based hybrid panel is presented in Figure 1. 


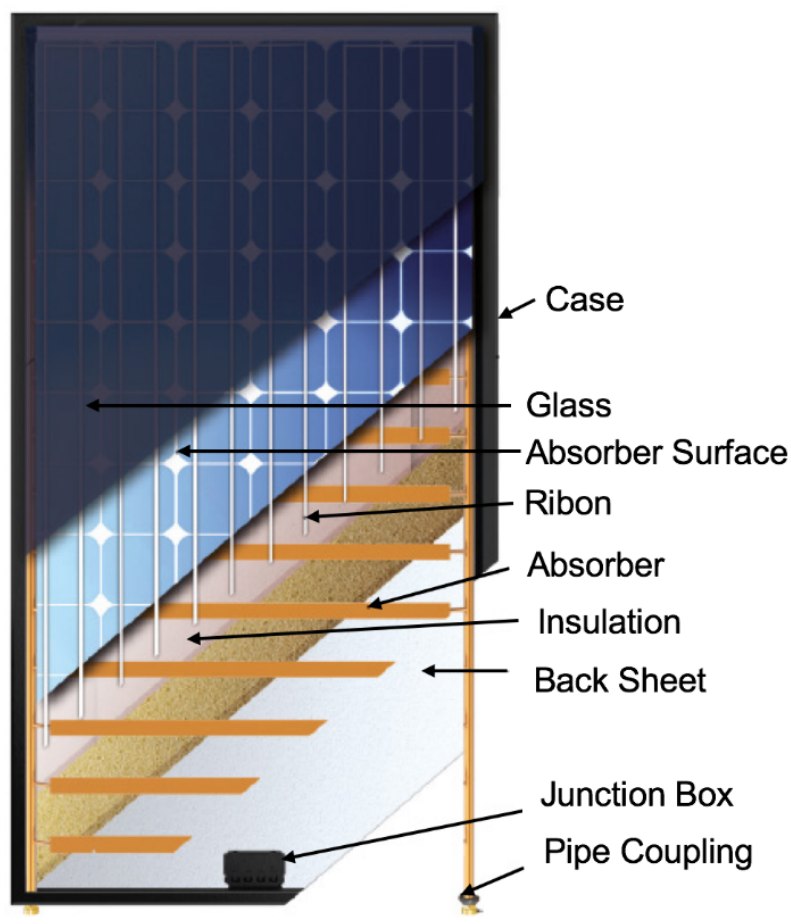

Figure 1: Liquid-Based HYBRID Panel Schematic [10]

Air-based hybrid panels operate similarly to liquid-based panels, but use air to transport heat from the panel to the thermal load. While these panels operate less efficiently than liquidbased panels, with a thermal efficiency range of $24 \%$ to $34 \%$ [5], they offer advantages related to low construction and maintenance costs [6]. Air-based hybrid panels can be constructed as individual units or as continuous arrays. Individual units must be connected by a ducting network, which can be connected in series or in parallel [11]. Alternatively, a panel array with no ductwork between panels can be constructed, which has a continuous airgap that runs underneath the panels, and can be constructed using off-the-shelf PV modules with a mounting system [12]. These continuous arrays may also act as the exterior surface of a building, and in that case can be referred to as a building integrated PVT (BIPVT) system [13]. These systems are often used to preheat ventilation air for buildings [14], and can also be used in conjunction with heat pumps to boost overall system operating efficiency in cold-climates [15]. Today, much of the research for 
air-based hybrid panels is related to heat transfer enhancements to improve the ability of air to remove heat from the panel [5]. A schematic of a typical air-based hybrid panel is presented in Figure 2.

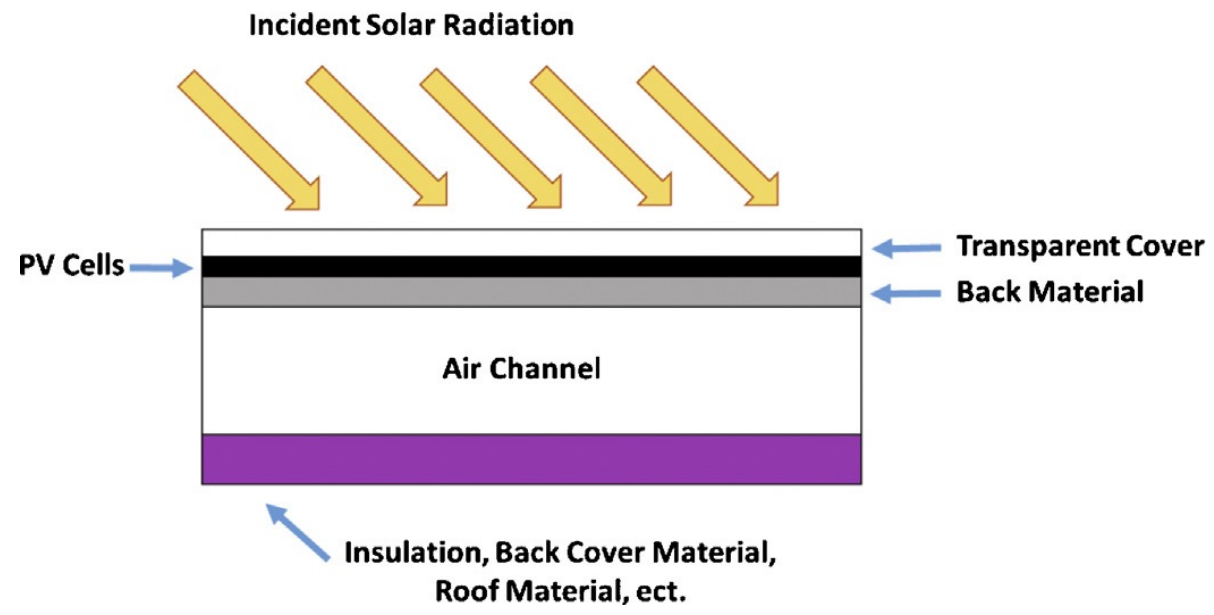

Figure 2: Air-based HYBRID schematic [15]

\subsection{Electrical performance modelling}

The electrical performance of a hybrid panel is assumed to be a function of the PV cell temperature. In most cases, the electrical performance of a PV panel is determined in accordance with the IEC 61215 testing standard, which results in the panel electrical efficiency as a function of the panel temperature being known [16]. For hybrid panels, the average of the panel inlet and outlet fluid temperatures are used since they are in close proximity to the PV, although the PV cell temperature is often higher than this value [8]. The general form of the electrical efficiency equation is given by Equation (1).

$$
\eta_{e}=\eta_{e_{\text {ref }}}\left(1-\alpha\left(T_{\text {panel }}-T_{\text {ref }}\right)\right)=\frac{\dot{E}}{G A_{\text {panel }}}
$$


where $\eta_{e}$ is the electrical efficiency of the panel at the panel temperature of interest $\left(T_{\text {panel }}\right)$, $\eta_{e_{r e f}}$ is the panel electrical efficiency at the panel reference temperature $\left(T_{r e f}\right), \alpha$ is the panel temperature coefficient, and $\dot{E}$ is the electrical power generated by the panel. The panel reference efficiency, panel reference temperature, and the panel temperature coefficient are all typically provided by the manufacturer. However, in cases when only the panel reference performance is provided, the panel temperature coefficient $(\alpha)$ can be assumed in the range of $0.37 \% / \mathrm{K}$ to 0.52 $\% / \mathrm{K}$ if crystalline silicon encapsulated solar cells are used [17]. When making this assumption, it is important to ensure that similar panel construction and PV cell material are implemented in the panel being analyzed.

\subsection{Thermal performance modelling}

The thermal performance of hybrid panels is typically modelled using one of three different approaches. These approaches will be discussed in Sections 1.4.1 to 1.4.3.

\subsubsection{Detailed finite element models}

The first approach is based upon a detailed finite element model of the panel, wherein each of the components in the panel is broken into small elements, and the interaction between each of these elements is accounted for numerically. These interactions include conductive, convective, and radiative heat exchange between elements, and between elements and the environment. The fluid flow within the panel can also be modelled using computational fluid dynamics (CFD), to ensure that the effects of variable fluid temperature, variable fluid flow velocity, and non-uniform panel temperature are considered [18]. This modelling technique requires that the detailed construction of the panel is known, and requires highly specialized 
software. Estimation of panel performance has been within 2\% of experimental values [19], which can be useful when designing a new solar panel, or when trying to learn about the detailed performance of a single panel component. However, the detail in this type of model is not always necessary to accurately estimate overall panel performance; a simplified component-level model may suffice.

\subsubsection{Component-level models}

The second modelling approach is based upon an energy balance for each of the major components in the panel [20] [21] [22]. Each of the components, such as the cover glass, insulation, fluid tubes, absorber plate, and PV cells, are given averaged material, optical, and geometric properties. The fluid within the panel is also given averaged characteristics, including specific heat capacity, temperature, density, and convection coefficient. The panel performance is then modelled based upon the interaction between each of these major components, the fluid, and the environment. This modelling technique has allowed for the overall performance of the panel to be estimated within $4.3 \%$ of experimental values [3], and can account for the selection of different panel components and operating conditions. However, while this technique can estimate panel performance for a wide variety of conditions and panel designs, manufacturers often do not release such detailed panel information, and instead only release the second-order efficiency parameters.

\subsubsection{Second-order efficiency models}

The third approach, which is also the focus of this paper, is the second-order efficiency model. This model is the most simplified of the models discussed to this point, and is used to 
estimate the thermal efficiency of the panel as a function of the fluid temperature within the panel, and the incident solar irradiation [1]. The general form of the second-order efficiency equation is presented in Equations (2) and (3), and is derived based upon a convective and radiative energy balance for a solar thermal panel [2].

$$
\begin{gathered}
\eta_{t h}=\eta_{0}+a_{1} T_{r}+a_{2} T_{r}^{2} G=\frac{\dot{Q}_{\text {panel }}}{G A_{\text {panel }}} \\
T_{r}=\frac{\left(T_{m}-T_{a}\right)}{G}
\end{gathered}
$$

where $T_{r}$ is the panel reduced temperature, $\eta_{0}, a_{1}$, and $a_{2}$ are the panel performance coefficients, $\dot{Q}_{\text {panel }}$ is the thermal power generated by the panel, $A_{\text {panel }}$ is the panel area used in the thermal efficiency parameter determination, $T_{m}$ is the mean of the panel inlet fluid temperature $\left(T_{i n}\right)$ and outlet fluid temperature $\left(T_{\text {out }}\right)$, and $G$ is the incident solar irradiation on the panel. The panel performance coefficients are derived from standard test condition results, and by performing a regression curve fit to Equation (2).

Using the panel thermal efficiency, the temperature change of the fluid as it passes through the panel can be found using Equation (4).

$$
\dot{Q}_{\text {panel }}=\eta_{\text {th }} G A_{\text {panel }}=\dot{m} c_{p}\left(T_{\text {out }}-T_{\text {in }}\right)
$$

where $\dot{m}$ is the mass flow rate of the fluid in the panel, and $c_{p}$ is the specific heat capacity of the fluid in the panel. 
This overall solar panel thermal performance estimation method is widely accepted in the literature, and in industry, to estimate panel thermal output. A study by Rad et al. [23] investigated using seasonal borehole energy storage with a solar array, and the second-order efficiency model was used to estimate solar energy generation. A study by Fine et al. [24] utilized the second-order efficiency model to determine the optimal quantity of solar panels for ground source heat pump systems. Another study by Khan et al. [25] used this analysis method to estimate solar panel performance when used with an absorption cooling system. This method is also referenced in the American Society of Heat Cooling and Refrigeration in their solar analysis standard [26], which is often used when designing solar energy systems. Lastly, hybrid panel manufacturers also use this method to characterize the thermal performance of their panels, and they typically publish the performance coefficients for use by system designers [27]. However, one major drawback compared to the more detailed models is that experimental data or detailed simulation data are required to generate the performance coefficients. Also, as previously mentioned, manufacturers are not required to provide thermal performance data when the panel is operating in hybrid mode, or thermal-only mode. Studies in the literature [28] [29] [30] [31] have shown that the thermal performance of a hybrid panel is different between these two modes. These differences will be discussed in Section 1.5.

\subsection{Effect of electrical energy generation on thermal performance}

Most studies in the literature that discuss the effect of electrical energy generation on hybrid panel thermal performance are in addition to the main topics of these articles. For example, a study by Dupeyrat et al. [28] performed characterization tests of a hybrid panel, with and without electrical energy generation, and found a difference in the panel thermal efficiency 
for the two cases. However, the purpose of this article was to assess the use of the panel with a solar water heating system, and an investigation into this generation difference was not presented. Similarly, a study by Yandri [29] mentioned that the thermal performance of a hybrid panel in these different operating modes can change by $4 \%$ to $12 \%$, depending on panel design and operating condition. This study by Yandri [29] also looked into how the thermal performance of a hybrid panel varied as a function of operating conditions, and included outdoor characterization tests. Yandri [29] found that at most panel reduced temperatures, the thermal efficiency of a hybrid panel will be higher when the panel is in thermal-only mode. However, Yandri [29] also found that at high irradiation levels, the thermal efficiency of a hybrid panel, when in hybrid mode, can exceed the thermal efficiency in thermal-only mode. Yandri [29] attributes this behavior at high irradiation levels to internal heating within the PV cells due to electrical current re-circulation, which improves heat transfer to the fluid circulating within the panel.

Furthermore, each of these studies supports the need to characterize the impact that the different operating modes have on the thermal performance of a hybrid panel. This paper will approach this need to characterize these impacts by presenting a modification method that can be used with the second-order efficiency model. This model was selected for use because of its wide-spread adoption, and ease of use. This modification method will provide a tool for designers and researchers to estimate the thermal performance of a hybrid panel when operating in a mode that differs from that used to generate the manufacturer provided characterization parameters.

\section{Thermal efficiency modification methodology}


The proposed thermal efficiency modification methodology requires that both the thermal performance and electrical performance characteristics of a hybrid panel are known. The thermal performance is assumed to be given as the second-order efficiency parameters, which are typically provided by panel manufacturers. The electrical performance is assumed to be given as the panel temperature coefficient and reference temperature, which are also typically provided by the manufacturer.

There are two possible cases that must be investigated when modifying the thermal efficiency. The first case is when panel performance data is available from hybrid operation mode, but thermal-only operation is required. When this case occurs, it is proposed that the electrical power that would have been generated by the panel becomes an additional energy flux, which then becomes available to be converted by the panel into thermal power. To complete this modification for the first operating case, a modified solar flux $\left(G_{1}{ }^{\prime}\right)$ must be determined using Equation (5).

$$
G_{1}^{\prime}=G+\eta_{e} G
$$

Next, a modified panel thermal efficiency $\left(\eta_{t h}{ }^{\prime}\right)$ and reduced temperature $\left(T_{r}{ }^{\prime}\right)$ can be found using Equations (6) and (7) respectively.

$$
\begin{gathered}
\eta_{t h}{ }^{\prime}=\eta_{0}+a_{1} T_{r}^{\prime}+a_{2} T_{r}^{\prime 2} G^{\prime} \\
T_{r}^{\prime}=\frac{\left(T_{m}-T_{a}\right)}{G^{\prime}}
\end{gathered}
$$


Lastly, the modified thermal power generated by the panel $\left(\dot{Q}_{\text {panel }}{ }^{\prime}\right)$ can be determined using Equation (8).

$$
\dot{Q}_{\text {panel }}{ }^{\prime}=\eta_{t h}{ }^{\prime} G^{\prime} A_{\text {panel }}
$$

The second case occurs when panel performance data is available for thermal-only mode, but an application requires that the panel operate in hybrid mode. This modification process is similar to the first operating case, but instead of adding the estimated electrical power generation to the available solar flux, it must be subtracted. The calculation of the modified solar flux for the second operating case $\left(G_{2}^{\prime}\right)$ can be carried out using Equation (9), and is then used in Equations (6) through (8) to determine the modified thermal power output of the panel.

$$
G_{2}^{\prime}=G-\eta_{r} G
$$

This proposed modification methodology was used to analyze a hybrid panel that was tested using an indoor solar simulator. The details of this testing will be presented in Section 3.1, and the results from the modification technique will be presented in Section 3.2.

\section{Validation and implementation of the modification method}

\subsection{Experimental testing description and test results}

To validate the proposed modification methodology, an indoor solar simulator was used to generate thermal performance data for a hybrid panel in both operating modes. The hybrid panel that was studied during this testing campaign was the PowerTherm PVT panel from 
Solimpeks [10]. The PowerTherm is a flat plate, glazed, liquid-based hybrid solar panel. An image of the test setup is shown in Figure 3.

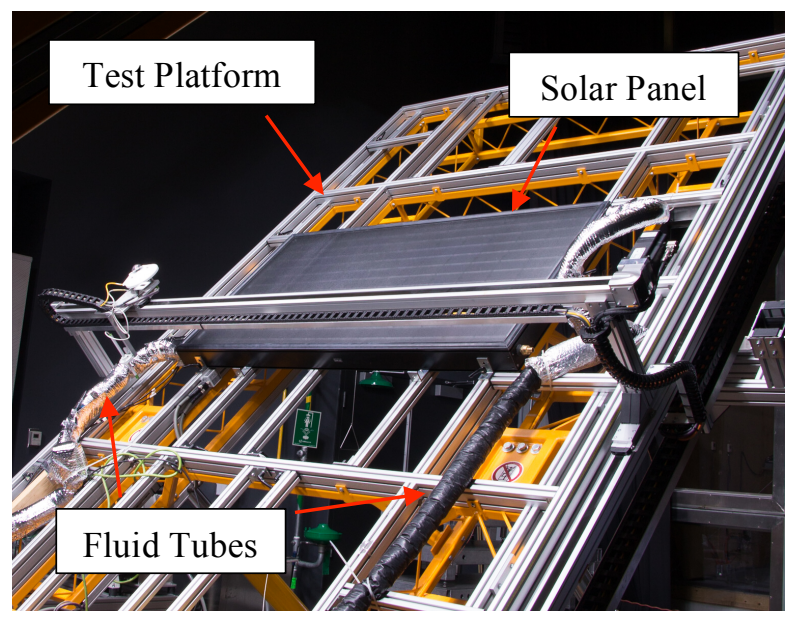

Figure 3: Photo of panel on solar simulator test platform

The test campaign was carried out at the Concordia University Centre for Zero Energy Building Studies in Montreal, Canada. The solar simulator consists of eight special metal halide lamps that meet EN 12975:2006 and ISO 9806-1:1994 standards, with an artificial sky. The lamps produce radiation with collimation of approximately $80 \%$, have $97 \%$ spatial uniformity, and $+/-1 \%$ temporal stability [32]. Temperature measurements were carried out using 1/10 DIN RTD's [32] with an average measurement accuracy of $+/-0.05 \mathrm{~K}$, and precision of $0.01 \mathrm{~K}$ [33]. Radiation measurements were carried out using a Kipp and Zonen CMP11 pyrometer, with a worst-case measurement accuracy of $+/-9 \mathrm{~W} / \mathrm{m}^{2}$ [34]. Water was used as the fluid within the panel, and mass flowrate measurements were carried out using an electromagnetic flow sensor with an accuracy of $+/-0.5 \%$ [32]. An air curtain was used to generate air motion that flowed parallel to the lamp-facing surface of the panel, and wind speed measurements were carried out using an anemometer with an accuracy of $+/-0.1 \mathrm{~m} / \mathrm{s}$. Electrical performance data was recorded 
using the DS-100C I-V curve tracer, which has a peak power measurement accuracy of $+/-1 \%$ [35].

Using the specifications for each sensor, the maximum and minimum of each calculated parameter as a function of measurement uncertainty was determined. The maximum reduced temperature $\left(T_{r_{\text {max }}}\right)$ and minimum reduced temperature $\left(T_{r_{\text {min }}}\right)$ were calculated using Equations (10) and (11), which are derived from Equation (3).

$$
\begin{gathered}
T_{r_{\text {max }}}=\frac{\left(T_{m}-T_{a}\right)_{\text {measured }}+0.1 \mathrm{~K}}{G_{\text {measured }}-9 \mathrm{~W} / \mathrm{m}^{2}} \\
T_{r_{\text {min }}}=\frac{T_{m}-T_{a}-0.1 \mathrm{~K}}{G_{\text {measured }}+9 \mathrm{~W} / \mathrm{m}^{2}}
\end{gathered}
$$

The maximum useful heat generated $\left(\dot{Q}_{\max }\right)$ and minimum useful heat generated $\left(\dot{Q}_{\min }\right)$ by the panel were calculated using Equations (12) and (13), which are derived from Equation (4).

$$
\begin{gathered}
\dot{Q}_{\text {max }}=\frac{1.005 \dot{Q}_{\text {measured }}\left[\left(T_{\text {out }}-T_{\text {in }}\right)_{\text {mesaured }}+0.1 \mathrm{~K}\right]}{\left(T_{\text {out }}-T_{\text {in }}\right)_{\text {mesaured }}} \\
\dot{Q}_{\text {min }}=\frac{0.995 \dot{Q}_{\text {measured }}\left[\left(T_{\text {out }}-T_{\text {in }}\right)_{\text {mesaured }}-0.1 \mathrm{~K}\right]}{\left(T_{\text {out }}-T_{\text {in }}\right)_{\text {mesaured }}}
\end{gathered}
$$

The maximum thermal efficiency $\left(\eta_{t h_{\text {max }}}\right)$ and minimum thermal efficiency $\left(\eta_{t h_{\text {min }}}\right)$ were then found using Equations (14) and (15).

$$
\eta_{t h_{\max }}=\frac{\dot{Q}_{\max }}{G_{\min } A_{\text {panel }}}
$$




$$
\eta_{t h_{\text {min }}}=\frac{\dot{Q}_{\text {min }}}{G_{\text {max }} A_{\text {panel }}}
$$

The maximum electrical efficiency $\left(\eta_{e_{\max }}\right)$ and minimum electrical efficiency $\left(\eta_{e_{\min }}\right)$ of the panel were then found using Equations (16) and (17).

$$
\begin{gathered}
\eta_{e_{\text {max }}}=\frac{1.01 \dot{E}_{\text {measured }}}{G_{\text {min }} A_{\text {panel }}} \\
\eta_{e_{\text {min }}}=\frac{0.99 \dot{E}_{\text {measured }}}{G_{\text {max }} A_{\text {panel }}}
\end{gathered}
$$

A total of 22 tests were carried out in which the panel was allowed to reach steady state. The steady state condition was defined as when the water outlet temperature from the panel changed by less than $0.01 \mathrm{~K}$ per minute, for at least two minutes. Upon test completion, an average of each measured parameter over the last $120 \mathrm{~s}$ of each test was used to generate a data point for each parameter for each test. A summary of the averaged test data is presented in Table 1. Note that an electrical power production measurement was not recorded for test 5 , but peak power tracking was active. 
Table 1: Experiment test results

\begin{tabular}{|c|c|c|c|c|c|c|c|c|c|c|}
\hline Mode & $\begin{array}{c}\text { Test } \\
\text { Number }\end{array}$ & $\begin{array}{c}\text { Wind } \\
\text { Speed } \\
(\mathrm{m} / \mathrm{s})\end{array}$ & $\begin{array}{l}\text { Water } \\
\text { Mass } \\
\text { Flow } \\
\text { Rate } \\
(\mathrm{kg} / \mathrm{h})\end{array}$ & $\begin{array}{c}\text { Solar } \\
\text { Flux } \\
\left(\mathrm{W} / \mathrm{m}^{2}\right)\end{array}$ & $\begin{array}{l}\text { Water } \\
\text { Inlet } \\
\text { Temp. } \\
\left({ }^{\circ} \mathrm{C}\right)\end{array}$ & $\begin{array}{c}\text { Water } \\
\text { Outlet } \\
\text { Temp. } \\
\left({ }^{\circ} \mathrm{C}\right)\end{array}$ & $\begin{array}{c}\text { Mean } \\
\text { Fluid } \\
\text { Temp. } \\
\left({ }^{\circ} \mathrm{C}\right)\end{array}$ & $\begin{array}{l}\text { Ambient } \\
\text { Temp. } \\
\left({ }^{\circ} \mathrm{C}\right)\end{array}$ & $\begin{array}{c}\text { Useful } \\
\text { Heat } \\
\text { Gain } \\
(\mathrm{W})\end{array}$ & $\begin{array}{c}\text { Electrical } \\
\text { Power } \\
\text { Output } \\
\text { (W) }\end{array}$ \\
\hline \multirow{12}{*}{ Hybrid } & 1 & 2.6 & 102.6 & 1062 & 21.9 & 27.64 & 24.77 & 19.66 & 683.7 & 145 \\
\hline & 2 & 2.6 & 102.8 & 1062 & 13.57 & 19.86 & 16.72 & 19.72 & 751 & 149.5 \\
\hline & 3 & 2.6 & 102.6 & 1062 & 40.37 & 44.84 & 42.61 & 19.62 & 532.3 & 135.9 \\
\hline & 4 & 2.6 & 104.4 & 1062 & 59.23 & 62.46 & 60.85 & 20.3 & 391.6 & 127 \\
\hline & 5 & 2.6 & 102.7 & 899 & 13.16 & 18.34 & 15.75 & 19.13 & 618 & \\
\hline & 6 & 2.6 & 103.7 & 899 & 21.49 & 26.2 & 23.85 & 19.19 & 567.1 & 124.72 \\
\hline & 7 & 2.6 & 102.8 & 899 & 40.23 & 43.95 & 42.09 & 19.24 & 444.6 & 114.1 \\
\hline & 8 & 2.6 & 103.1 & 899 & 58.99 & 61.48 & 60.24 & 20.12 & 299.4 & 108.1 \\
\hline & 9 & 2.6 & 102.6 & 1301 & 40.77 & 46.44 & 43.61 & 20.02 & 675.2 & 163.8 \\
\hline & 10 & 2.6 & 103.2 & 1301 & 22.21 & 29.12 & 25.67 & 20.3 & 828.2 & 174.9 \\
\hline & 11 & 2.6 & 103.3 & 1301 & 13.87 & 21.23 & 17.55 & 20.47 & 883.8 & 180.2 \\
\hline & 12 & 2.6 & 103 & 1301 & 59.46 & 63.98 & 61.72 & 21.01 & 540.7 & 151.9 \\
\hline \multirow{10}{*}{$\begin{array}{c}\text { Thermal- } \\
\text { Only }\end{array}$} & 13 & 2.6 & 102.6 & 1062 & 13.9 & 21.12 & 17.51 & 19.97 & 860.8 & 0 \\
\hline & 14 & 2.6 & 102.5 & 1062 & 22.18 & 28.79 & 25.49 & 19.8 & 786.6 & 0 \\
\hline & 15 & 2.6 & 102.5 & 1062 & 21.98 & 28.38 & 25.18 & 19.79 & 760.8 & 0 \\
\hline & 16 & 2.6 & 103.1 & 1062 & 40.64 & 45.87 & 43.26 & 19.95 & 625.6 & 0 \\
\hline & 17 & 2.6 & 103.2 & 899 & 13.34 & 19.26 & 16.30 & 19.18 & 709.9 & 0 \\
\hline & 18 & 2.6 & 103.7 & 899 & 21.67 & 27.07 & 24.37 & 19.16 & 650 & 0 \\
\hline & 19 & 2.6 & 102.8 & 899 & 40.3 & 44.59 & 42.45 & 19.2 & 511.4 & 0 \\
\hline & 20 & 2.6 & 102.7 & 1301 & 40.96 & 47.6 & 44.28 & 20.22 & 791.2 & 0 \\
\hline & 21 & 2.6 & 103.4 & 1301 & 22.45 & 30.39 & 26.42 & 20.24 & 952 & 0 \\
\hline & 22 & 2.6 & 102.9 & 1301 & 14.06 & 22.46 & 18.26 & 20.59 & 1004.5 & 0 \\
\hline
\end{tabular}

Using this test data, and the maximum potential measurement errors from each of the sensors, the resulting panel reduced temperatures, thermal efficiencies, and electrical efficiencies were calculated. The results shown in Table 2 summarize these calculated efficiencies, along with the uncertainties for each of the parameters. 
Table 2: Resulting thermal and electrical efficiencies

\begin{tabular}{|c|c|c|c|c|}
\hline Mode & $\begin{array}{c}\text { Test } \\
\text { Number }\end{array}$ & $\begin{array}{c}\text { Reduced } \\
\text { Temperature } \\
\left(\mathrm{Km}^{2} / \mathrm{W} \times 1000\right)\end{array}$ & $\begin{array}{c}\text { Thermal } \\
\text { Efficiency } \\
(\%)\end{array}$ & Electrical (\%) \\
\hline \multirow{12}{*}{ Hybrid } & 1 & $4.81+/-0.14$ & $46.0+/-1.4$ & $9.75+/-0.18$ \\
\hline & 2 & $-2.83+/-0.07$ & $50.5+/-1.5$ & $10.06+/-0.19$ \\
\hline & 3 & $21.64+/-0.28$ & $35.8+/-1.3$ & $9.14+/-0.17$ \\
\hline & 4 & $38.18+/-0.42$ & $26.3+/-1.2$ & $8.54+/-0.16$ \\
\hline & 5 & $-3.76+/-0.07$ & $49.1+/-1.7$ & \\
\hline & 6 & $5.18+/-0.16$ & $45.1+/-1.7$ & $9.91+/-0.20$ \\
\hline & 7 & $25.42+/-0.37$ & $35.3+/-1.5$ & $9.07+/-0.18$ \\
\hline & 8 & $44.62+/-0.56$ & $23.8+/-1.3$ & $8.59+/-0.17$ \\
\hline & 9 & $18.13+/-0.20$ & $37.1+/-1.1$ & $8.99+/-0.15$ \\
\hline & 10 & $4.12+/-0.11$ & $45.5+/-1.2$ & $9.60+/-0.16$ \\
\hline & 11 & $-2.24+/-0.06$ & $48.5+/-1.2$ & $9.89+/-0.17$ \\
\hline & 12 & $31.29+/-0.30$ & $29.7+/-1.0$ & $8.34+/-0.14$ \\
\hline \multirow{10}{*}{$\begin{array}{c}\text { Thermal- } \\
\text { Only }\end{array}$} & 13 & $-2.32+/-0.08$ & $57.9+/-1.6$ & 0 \\
\hline & 14 & $5.35+/-0.14$ & $52.9+/-1.5$ & 0 \\
\hline & 15 & $5.08+/-0.14$ & $51.2+/-1.5$ & 0 \\
\hline & 16 & $21.94+/-0.28$ & $42.1+/-1.4$ & 0 \\
\hline & 17 & $-3.20+/-0.08$ & $56.4+/-1.8$ & 0 \\
\hline & 18 & $5.80+/-0.17$ & $51.6+/-1.8$ & 0 \\
\hline & 19 & $25.86+/-0.37$ & $40.6+/-1.6$ & 0 \\
\hline & 20 & $18.49+/-0.21$ & $43.4+/-1.2$ & 0 \\
\hline & 21 & $4.75+/-0.11$ & $52.3+/-1.3$ & 0 \\
\hline & 22 & $-1.79+/-0.06$ & $55.1+/-1.3$ & 0 \\
\hline
\end{tabular}

Panel thermal and electrical efficiencies as functions of panel temperatures and are shown in Figure 4, along with regression fits to each of the data sets. 

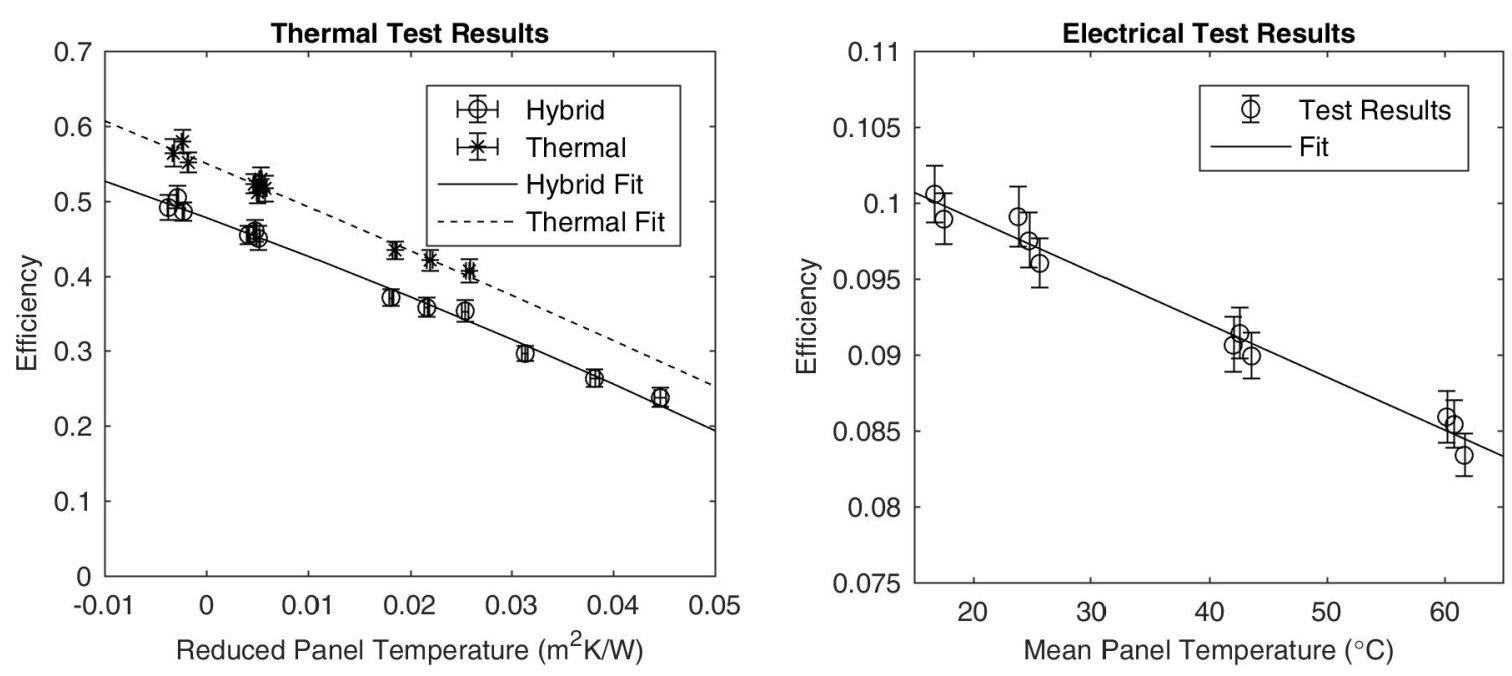

Figure 4: Thermal test results (left), Electrical test results (right)

It can be seen from Figure 4 that both the panel thermal and electrical efficiencies decrease with increasing panel temperature. The thermal efficiency results support that the panel operating mode does have an impact on the panel thermal performance, which will be discussed in more detail in Section 3.2. As the reduced temperature of the panel increases, the thermal efficiency decreases, which is expected based upon other results found in the literature [23] [24] [25]. Similarly, the electrical performance of the solar panel decreases as the mean panel temperature increases, which is also expected based upon typical PV panel performance [8].

The regression analysis was completed using the method of least squares to determine the most suitable set of coefficients for an equation of interest [36]. The coefficients for the secondorder thermal efficiency curve and the coefficients for the electrical efficiency curve are presented in Table 3. The resulting R-square and root mean square error (RMSE) for each of the fits are also presented in Table 3.

Table 3: Panel efficiency equation coefficients from test results

\begin{tabular}{|c|c|c|c|}
\hline Data Set & Equation & R-Square & RMSE \\
\hline Hybrid - Thermal Data & $\eta_{t h}=0.478-5.00 T_{r}-0.0136 T_{r}^{2} G$ & 0.9935 & 0.008 \\
\hline Thermal-Only - Thermal Data & $\eta_{t h}=0.550-5.73 T_{r}-0.00433 T_{r}^{2} G$ & 0.9814 & 0.010 \\
\hline
\end{tabular}




\begin{tabular}{|c|c|c|c|}
\hline Hybrid - Electrical Data & $\eta_{e}=0.1059\left(1-0.00328 T_{m}\right)$ & 0.9796 & 0.001 \\
\hline
\end{tabular}

\subsection{Application of the thermal performance modification technique}

Using the resulting correlations, and the environmental conditions from the testing campaign, the modification technique described in Section 2 was utilized to generate modified thermal performance data for validation purposes. The validation process was carried out by estimating the measured thermal performance of the panel while using the correlation from the opposing operation mode. The first validation case was carried out using hybrid mode measured environmental test data as inputs to Equations (6) with coefficients that were determined from thermal-only mode test data. Then, using the modification process, a prediction of hybrid mode thermal performance was completed and compared to the measured hybrid mode thermal performance test data. The results of this first validation case are presented in Table 4.

Table 4: Results of first validation case

\begin{tabular}{|c|c|c|c|c|c|}
\hline $\begin{array}{c}\text { Test } \\
\text { Number }\end{array}$ & $\begin{array}{c}\text { Measured } \\
\text { Useful } \\
\text { Heat Gain } \\
(\mathrm{W})\end{array}$ & $\begin{array}{c}\text { Estimated } \\
\text { Electrical } \\
\text { Efficiency } \\
\text { from } \\
\text { Correlation }\end{array}$ & $\begin{array}{c}\text { Modified } \\
\text { Solar } \\
\text { Flux } \\
\left(\mathrm{W} / \mathrm{m}^{2}\right)\end{array}$ & $\begin{array}{c}\text { Modified } \\
\text { Useful } \\
\text { Heat Gain } \\
(\mathrm{W})\end{array}$ & $\begin{array}{c}\text { Relative Error } \\
\text { with } \\
\text { Modification }\end{array}$ \\
\hline 1 & 683.7 & $9.73 \%$ & 959 & 697 & $1.95 \%$ \\
\hline 2 & 751 & $10.0 \%$ & 956 & 760 & $1.19 \%$ \\
\hline 3 & 532.3 & $9.11 \%$ & 965 & 556 & $4.39 \%$ \\
\hline 4 & 391.6 & $8.48 \%$ & 972 & 413 & $5.51 \%$ \\
\hline 5 & 618 & $10.0 \%$ & 809 & 650 & $5.14 \%$ \\
\hline 6 & 567.1 & $9.76 \%$ & 811 & 587 & $3.54 \%$ \\
\hline 7 & 444.6 & $9.13 \%$ & 817 & 443 & $-0.46 \%$ \\
\hline 8 & 299.4 & $8.50 \%$ & 823 & 302 & $0.81 \%$ \\
\hline 9 & 675.2 & $9.08 \%$ & 1183 & 718 & $6.38 \%$ \\
\hline 10 & 828.2 & $9.70 \%$ & 1175 & 861 & $4.01 \%$ \\
\hline 11 & 883.8 & $9.98 \%$ & 1171 & 925 & $4.68 \%$ \\
\hline 12 & 540.7 & $8.45 \%$ & 1191 & 581 & $7.36 \%$ \\
\hline & & & & Average & $3.71 \%$ \\
\hline
\end{tabular}


Based on the results presented in Table 4 for the first validation case, it can be seen that when the modification process is used to estimate hybrid mode performance with the thermalonly curve, estimates can be obtained with an average absolute relative error of $3.7 \%$. The minimum absolute error of $0.46 \%$ resulted from test 7 , which operated with a mean panel temperature of $42^{\circ} \mathrm{C}$, and a solar flux of $900 \mathrm{~W} / \mathrm{m}^{2}$. Alternatively, the maximum absolute error was $7.36 \%$ for test 12 , which operated with a mean panel temperature of $62^{\circ} \mathrm{C}$, and a solar flux of $1,300 \mathrm{~W} / \mathrm{m}^{2}$. Aside from test 7 , each of the estimations using the modification technique overpredicted the thermal power output of the solar panel.

The second validation case was carried out using thermal-only mode measured environmental test data as inputs to Equations (6) with coefficients that were determined from hybrid mode test data. Then, using the modification process, a prediction of thermal-only mode thermal performance performed and compared to the measured thermal-only mode thermal performance test data. The results of this second validation case are presented in Table 5 .

Table 5: Results of second validation case

\begin{tabular}{|c|c|c|c|c|c|}
\hline $\begin{array}{c}\text { Test } \\
\text { Number }\end{array}$ & $\begin{array}{c}\text { Measured } \\
\text { Useful } \\
\text { Heat Gain } \\
(\mathrm{W})\end{array}$ & $\begin{array}{c}\text { Estimated } \\
\text { Electrical } \\
\text { Efficiency } \\
\text { from } \\
\text { Correlation }\end{array}$ & $\begin{array}{c}\text { Modified } \\
\text { Solar } \\
\text { Flux } \\
\left(\mathrm{W} / \mathrm{m}^{2}\right)\end{array}$ & $\begin{array}{c}\text { Modified } \\
\text { Useful } \\
\text { Heat Gain } \\
(\mathrm{W})\end{array}$ & $\begin{array}{c}\text { Relative Error } \\
\text { with } \\
\text { Modification }\end{array}$ \\
\hline 13 & 860.8 & $9.98 \%$ & 1168 & 813 & $-5.50 \%$ \\
\hline 14 & 786.6 & $9.71 \%$ & 1165 & 754 & $-4.15 \%$ \\
\hline 15 & 760.8 & $9.72 \%$ & 1165 & 756 & $-0.61 \%$ \\
\hline 16 & 625.6 & $9.09 \%$ & 1159 & 616 & $-1.47 \%$ \\
\hline 17 & 709.9 & $10.0 \%$ & 989 & 694 & $-2.19 \%$ \\
\hline 18 & 650 & $9.74 \%$ & 987 & 636 & $-2.20 \%$ \\
\hline 19 & 511.4 & $9.12 \%$ & 981 & 496 & $-3.05 \%$ \\
\hline 20 & 791.2 & $9.05 \%$ & 1419 & 788 & $-0.42 \%$ \\
\hline 21 & 952 & $9.67 \%$ & 1427 & 929 & $-2.43 \%$ \\
\hline 22 & 1004.5 & $9.96 \%$ & 1431 & 992 & $-1.29 \%$ \\
\hline & Average & & $-2.33 \%$ \\
\hline
\end{tabular}


Based on the results presented in Table 5 for the second validation case, it can be seen that when the modification process is used to estimate thermal-only performance with the hybrid curve, estimates can be obtained with an average absolute relative error of $2.33 \%$. The minimum absolute error of $0.42 \%$ resulted from test 20 , which operated with a mean panel temperature of $44^{\circ} \mathrm{C}$, and a solar flux of $1,300 \mathrm{~W} / \mathrm{m}^{2}$. Alternatively, the maximum absolute error of $5.5 \%$ resulted from test 13 , which operated with a mean panel temperature of $62^{\circ} \mathrm{C}$, and a solar flux of $1,300 \mathrm{~W} / \mathrm{m}^{2}$. Each of the estimations using the modification technique for the second validation case under-predicted the thermal power output of the solar panel, which is an opposite result compared to the first validation case.

For additional insight, a calculation of the estimated thermal performance of the panel using the unmodified thermal performance correlations was also completed. The unmodified thermal-only correlation was used with the hybrid mode test data, and the unmodified hybrid mode correlation was used with the thermal-only test data. A summary of the resulting relative errors between these estimations and the measured test data is presented in Table 6, along with the previously presented relative errors using the modification process for comparison.

Table 6: Unmodified performance estimations for comparison

\begin{tabular}{|c|c|c|c|}
\hline \multirow{3}{*}{$\begin{array}{c}\text { Validation } \\
\text { Case }\end{array}$} & $\begin{array}{c}\text { Test } \\
\text { Number }\end{array}$ & $\begin{array}{c}\text { Relative } \\
\text { Error with } \\
\text { Modification }\end{array}$ & $\begin{array}{c}\text { Relative } \\
\text { Error } \\
\text { without } \\
\text { Modification }\end{array}$ \\
\hline \multirow{6}{*}{1} & 1 & $1.95 \%$ & $13.6 \%$ \\
\cline { 2 - 4 } & 2 & $1.19 \%$ & $12.1 \%$ \\
\cline { 2 - 4 } & 3 & $4.39 \%$ & $18.4 \%$ \\
\cline { 2 - 4 } & 4 & $5.51 \%$ & $23.2 \%$ \\
\cline { 2 - 4 } & 5 & $5.14 \%$ & $16.4 \%$ \\
\cline { 2 - 4 } & 6 & $3.54 \%$ & $15.5 \%$ \\
\cline { 2 - 4 } & 7 & $-0.46 \%$ & $13.8 \%$ \\
\cline { 2 - 4 } & 9 & $0.81 \%$ & $20.5 \%$ \\
\cline { 2 - 4 } & 10 & $6.38 \%$ & $19.8 \%$ \\
\cline { 2 - 4 } & 11 & $4.01 \%$ & $15.7 \%$ \\
\hline \multirow{6}{*}{} & $4.68 \%$ & $16.0 \%$ \\
\hline
\end{tabular}




\begin{tabular}{|c|c|c|c|}
\hline \multirow{4}{*}{} & 12 & $7.36 \%$ & $23.0 \%$ \\
\cline { 2 - 4 } & Average & $3.71 \%$ & $17.3 \%$ \\
\hline 13 & $-5.50 \%$ & $-15 \%$ \\
\cline { 2 - 4 } & 14 & $-4.15 \%$ & $-15 \%$ \\
\cline { 2 - 4 } & 15 & $-0.61 \%$ & $-12 \%$ \\
\cline { 2 - 4 } & 16 & $-1.47 \%$ & $-14 \%$ \\
\cline { 2 - 4 } & 17 & $-2.19 \%$ & $-12 \%$ \\
\cline { 2 - 4 } & 18 & $-2.20 \%$ & $-13 \%$ \\
\cline { 2 - 4 } & 19 & $-3.05 \%$ & $-16 \%$ \\
\cline { 2 - 4 } & 20 & $-0.42 \%$ & $-13 \%$ \\
\cline { 2 - 4 } & 21 & $-2.43 \%$ & $-13 \%$ \\
\cline { 2 - 4 } & 22 & $-1.29 \%$ & $-12 \%$ \\
\cline { 2 - 4 } & Average & $-2.33 \%$ & $-13.5 \%$ \\
\hline
\end{tabular}

Based on the results presented in Table 6, it was found that using the modification technique improves opposing mode thermal performance estimations for all tests. Using the unmodified thermal-only curve to estimate hybrid performance data results in an average estimation error of $17.3 \%$, compared to an average estimation error of $3.7 \%$ when using the modification technique. Similarly, using the unmodified hybrid mode curve to estimate thermalonly performance data results in an average estimation error of $13.5 \%$, compared to an average estimation error of $2.3 \%$ when using the modification technique. Furthermore, these experimental results validate that the modification technique is an effective method in predicting alternate mode thermal performance for a hybrid panel.

Lastly, correlations between relative error estimates using the modification technique and reduced temperature, solar flux, and panel mean temperature were also investigated. However, the R-square results for each of these correlations did not exceed 0.12 . Therefore, it was determined that there is no significant correlation between panel operating conditions and the error that results when using the modification technique.

\section{Conclusions}


Hybrid panel manufactures typically publish the second-order efficiency parameters for their products, which are often used by researchers and engineers to estimate overall panel thermal performance. However, based upon standard testing procedures, manufacturers are only required to characterize the thermal performance of hybrid panels in hybrid mode, or thermalonly mode. Due to this widespread use, and because of the need for alternate mode performance prediction, a modification technique for the second-order efficiency model was selected as the focus for this study.

The proposed modification method involves adjusting the available solar flux based upon the theoretical electrical efficiency of the panel. This modified flux is then used to determine a modified panel reduced temperature, and these two modified parameters can then be used with the manufacturer provided efficiency correlation. Using this modification method, the average estimating error was found to be $3.71 \%$ when using the modified thermal-only correlation to estimate hybrid mode performance, which results in a 13.5\% performance estimation improvement compared to not using the modification process. Similarly, when using the modification method with the hybrid mode correlation to estimate thermal-only performance, an average error of $2.33 \%$ was found, with an average improvement of $11.2 \%$ compared to not using the modification method. No strong correlation was found between estimation error and panel mean temperature, solar flux, or panel reduced temperature. Therefore, based upon the results of this study, the proposed modification method has been validated as an effective tool for estimating alternate mode hybrid solar panel thermal performance.

\section{Acknowledgements}


This research was undertaken, in part, thanks to funding from the Canada Research

Chairs program. We would like to thank the Concordia University Centre for Zero Energy Building Studies for their support during the testing campaign carried out for this study. We would also like to acknowledge the Natural Sciences and Engineering Research Council of Canada, and the Ontario Graduate Scholarship program for funding towards this research.

\section{Bibliography}

[1] ISO/TC 180 Solar energy, "ISO 9806:2017 Solar energy -- Solar thermal collectors -- test methods," International Organization for Standardization, 2017.

[2] D. J.A. and B. W.A., Solar Engineering of Thermal Processes - Second Edition, New York: Wiley-Interscience, 1991.

[3] R. Nasrin, M. Hasanuzzaman and N. Rahim, "Effect of high irradiation and cooling on power, energy and performance of a PVT system," Renewable Energy, no. 116, pp. 552$569,2018$.

[4] H. Ibrahim and N. Anani, "Variations of PV module parameters with irradiance and temperature," Energy Procedia, no. 134, pp. 276-285, 2017.

[5] T. M. Sathe and A. Dhoble, "A review on recent advancements in photovoltaic thermal techniques," Renewable and Sustainable Energy Reviews, no. 76, pp. 645-672, 2017.

[6] A. Kumar, P. Baredar and U. Qureshi, "Historical and recent development of photovoltaic thermal (PVT) technologies," Renewable and Sustainable Energy Reviews, no. 42, pp. 1428-1436, 2015.

[7] J. P. Fine, J. Friedman and S. B. Dworkin, "Detailed modeling of a novel photovoltaic thermal cascade heat pump domestic water heating system," Renewable Energy, no. 101, pp. 500-513, 2017.

[8] J. P. Fine, J. Friedman and S. B. Dworkin, "Transient analysis of a photovoltaic thermal heat input process with thermal storage," Appied Energy, vol. 160, pp. 308-320, 2015.

[9] DOW Chemical, "Engineering and Operating Guide for DOWTHERM SR-1 and DOWTHERM 4000 Inhibited Ethylene Glycol-based Heat Transfer Fluids," DOW Chemical, Midland, 2008.

[10] Solimpeks Solar Energy Corp., "Volther PowerTherm \& PowerVolt Datasheet," Solimpeks, Konya, 2016.

[11] V. Tomar, G. Tiwari and T. Bhatti, "Performance of different photovoltaic-thermal (PVT) configurations integrated on prototype test cells: An experimental approach," Energy Conversion and Management, no. 154, pp. 394-419, 2017.

[12] S. Bambrook and A. Sproul, "Maximising the energy output of a PVT air system," Solar 
Energy, no. 86, pp. 1857-1871, 2012.

[13] M. Debbarma, K. Sudhakar and P. Baredar, "Comparison of BIPV and BIPVT: A review," Resource-Efficient Technologies, no. 3, pp. 263-271, 2017.

[14] S. Tiwari and G. Tiwari, "Energy and exergy analysis of a mixed-mode greenhouse-type solar dryer, integrated with partially covered N-PVT air collector," Energy, no. 128, pp. 183-195, 2017.

[15] R. S. Kamel and A. S. Fung, "Modeling, simulation and feasibility analysis of residential BIPV/T+ASHP system in cold climate-Canada," Energy and Buildings, no. 82, pp. 758$770,2014$.

[16] IEC 61215, "International Standard IEC 61215: Crystalline silicon terrestrial photovoltaic (PV) modeules - design qualification and type approval," IEC, 2016.

[17] M. Akhsassi, A. El Fathi, N. Erraissi, N. Aarich, A. Bennouna, M. Raoufi and A. Outzourhit, "Experimental investigation and modeling of the thermal behavior of a solar PV module," Solar Energy Materials and Solar Cells, vol. 180, pp. 271-279, 2017.

[18] S. Hussain and S. J. Harrison, "Evaluation of thermal characteristics of a flat plate solar collector with a back mounted air channel," Applied Thermal Engineering, no. 123, pp. 940952, 2017.

[19] M. Lammle, T. Kroyer, S. Fortuin, M. Wiese and M. Hermann, "Development and modelling of highly-efficient PVT collectors with low-emissivity coatings," Solar Energy, no. 130, pp. 161-173, 2016.

[20] S. Bambrook and A. Sproul, "A solvable thermal circuit for modelling PVT air collectors," Solar Energy, no. 138, pp. 77-87, 2016.

[21] A. Fudholi, K. Sopian, M. H. Yazdi, M. H. Ruslan, A. Ibrahim and H. A. Kazem, "Performance analysis of photovoltaic thermal (PVT) water collectors," Energy Conversion and Management, no. 78, pp. 641-651, 2014.

[22] J. Antonanzas, A. d. Amo, A. Martinez-Gracia, A. Bayod-Rujula and F. Antonanzas-Torres, "Towards the optimization of convective losses in photovoltaic-thermal panels," Solar Energy, no. 116, pp. 323-336, 2015.

[23] F. M. Rad, A. S. Fung and M. A. Rosen, "An integrated model for designing a solar community heating system with borehole thermal storage," Energy for Sustainable Development, no. 36, pp. 6-15, 2017.

[24] J. P. Fine, H. V. Nguyen, J. Friedman, W. H. Leong and S. B. Dworkin, "A Simplified Ground Thermal Response Model for Analyzing Solar-Assisted Ground Source Heat Pump Systems," Energy Conversion and Management, Vols. TBD - Accepted Publication, 2018.

[25] M. S. A. Khana, A. W. Badarb, T. Talha, M. W. Khan and F. S. Butt, "Configuration based modeling and performance analysis of single effect solar absorption cooling system in TRNSYS," Energy Conversion and Management, no. 157, pp. 351-363, 2018.

[26] ASHRAE, ASHRAE Standard 93-2003 - Methods of testing to determine the performance of solar collectors, Atlanta: American Society of Heating Cooling and Refrigeration, 2003.

[27] G. Bellenda, "Powertherm Thermal Test Report," Solimpeks, Torino, 2011.

[28] P. Dupeyrata, C. Ménézob and S. Fortuin, "Study of the thermal and electrical performances of PVT solar hot water system," Energy and Buildings, no. 68, pp. 751-755, 2014.

[29] E. Yandri, "The effect of Joule heating to thermal performance of hybrid PVT collector 
during electricity generation," Renewable Energy, no. 111, pp. 344-352, 2017.

[30] T. Chow, W. He and J. Ji, "Hybrid photovoltaic-thermosyphon water heating system for residential application," Solar Energy, no. 80, pp. 298-306, 2006.

[31] A. Ghoneim, M. Aljanabi, A. Al-Hasan and M. A. M., "Yields Analysis and Environmental Evaluation of Combined Photovoltaic-Thermal Collector in Kuwait Climate," in Global Conference on Global Warming, Istanbul, 2008.

[32] K. Kapsis, "Modelling, Design and Experimental Study of Semi-Transparent Photovoltaic Windows for Commercial Building Applications - PhD Thesis," Concordia University, Montreal, 2016.

[33] Temperature Controls Ltd., "RTD accuracy - Class A, Class B, 1/3 DIN, 1/10 DIN," Temperature Controls Ltd., Sydney, 2018.

[34] Kipp and Zonen, "CMP Series Pyranometer Instruction Manual," Delft, 2016.

[35] DayStar Inc., "DS-100C I-V CURVE TRACER User Manual," Daystar Inc., Albuquerque, 2011.

[36] MathWorks, Inc, "Curve Fitting Toolbox Help Documentation," MathWorks, 2016. 